\title{
Does Economic Rationalization Decrease or Increase Accounting Professionals' Occupational Values?
}

\author{
Girts Racko ${ }^{1}$
}

Received: 4 April 2017 / Accepted: 30 October 2017 / Published online: 10 November 2017

(c) The Author(s) 2017. This article is an open access publication

\begin{abstract}
Following corporate accounting scandals there has been an increasing concern with understanding the factors that undermine the occupational values of accounting professionals, which emphasize self-transcendence in the pursuit of public good and openness to change in the pursuit of autonomy and creativity. Prior studies have demonstrated that these values are undermined in economically rationalized organizational environments. Our study advances this research by examining how accounting professionals' occupational values are influenced by the economic rationalization of countries where they are employed. While economic rationalization of countries is recognized as a key macrostructural, social-level influence on individual values, the theory is divided regarding its normative effects. While economic rationalization may decrease the priority of occupational values by transforming professional action in accordance with the calculative logic of economic rationality, it can also increase the priority of these values by providing resources necessary for freeing professionals from the material constraints of survival. We test these divergent insights using the European Social Survey data for 28 countries. Our results indicate that economic rationalization decrease accountants' occupational values beyond the effects of cultural values and work-related characteristics.
\end{abstract}

Keywords Accounting professionalism - Accounting ethics - Occupational values - Economic rationalization . Economic rationality

Girts Racko

girts.racko@wbs.ac.uk

1 Warwick Business School, University of Warwick, Coventry CV4 7AL, UK

\section{Introduction}

Corporate accounting scandals worldwide, such as Enron, Parmalat and Anglo Irish Bank, undermined public confidence in the moral character of the accounting profession (Mele et al. 2017; Satava et al. 2006). These scandals highlighted the importance of understanding environmental factors that affect accountants' commitment to the occupational values of professionalism (Jackling et al. 2007; Graafland and Van de Ven 2011), which emphasize independent client assessment oriented toward public good (Loeb 1988; Duska and Duska 2003). A fundamental assumption of the research on business ethics (Sen 1987; Ghoshal 2005; Ferraro et al. 2005) and professions (Ritzer and Walcak 1988; Freidson 2001; Timmermans and Berg 2003) is that these occupational values are undermined in vocational environments that are dominated by economic rationality. This is because economically rational action, in the most generic sense, standardizes human activity in accordance with the logic of instrumentally rational calculation that utilizes the most effective means to achieve self-interested ends (Huehn 2008; Dierksmeier 2011; Racko 2017a). Prior studies demonstrate how the occupational values of business professionals and students are undermined in business education programs, which are guided homogenously by economic rationality (Frank et al. 1993; Lynnette and Davis 2004; Ghoshal 2005; Wang et al. 2011; Huehn 2014; Racko et al. 2017). The practical implication of these studies is that socialization of occupational values is particularly important in economically rationalized study and work environments.

Our study advances the understanding of the normative effect of economically rationalized environments by examining the effect of the economic rationalization of countries on the occupational values of accounting professionals. This is important for two reasons. First, economic rationalization 
of countries is theoretically recognized as a key macrostructural force that influences individuals' values across distinct national cultures, organizational types and sectors of employment (Weber 1978; Hofstede 2001; Inglehart and Welzel 2005; Ferraro et al. 2005). Because in countries with a more rationalized national economy work is more homogenously guided by the values of economic rationality that emphasize instrumentally rational utilization of resources, people in these countries are more likely to act in an instrumentally rational way by using the most effective means to achieve self-interested ends (Weber 1978; Tonnies 1996; Ferraro et al. 2005; Ritzer 2011). In these countries, people are more likely to adopt calculative and strategic approach to human interaction and to be responsive to incentives that facilitate utility maximization. While economic rationalization is an important medium for the transmission of the values of economic rationality, its effects on accountants' values have not been examined.

Second, the theory concerning the normative effects of economic rationalization is inconsistent. On the one hand, economic rationalization may decrease the priority of accounting professionals' occupational values by reorganizing their mental processes in accordance with the calculative logic of economic rationality (Weber 1978; Tonnies 1996; Ritzer 2011; Racko 2011). Business professionals who internalize the values of economic rationality in economically rationalized work environments are likely to sacrifice their occupational concern with independence and public good to pursue their economic self-interest (Goshal 2005; Ferraro et al. 2005; Huehn 2014). On the other hand, economic rationalization can increase the commitment of business professionals to these occupational values by generating resources, which can increase their occupational autonomy and pro-social concern with public good by freeing them from the material necessities of survival (Lerner 1958; Inkeles and Smith 1974; Inglehart and Welzel 2005). We test these contradictory insights by examining the following research question: Does economic rationalization decrease or increase accounting professionals' occupational values?

The paper is structured as follows. In the next section, we highlight the occupational values of accounting professionals and present the hypotheses of the impact effect of economic rationalization on these values. Subsequently, we review the methods and findings. Finally, we consider the theoretical and practical implications of our findings.

\section{Theoretical Background: Values and Economic Rationalization}

We define human values as enduring normative standards about how life ought to be that determine human behavior (Rokeach 1973; Schwartz 1992). Human values are mutually irreconcilable and ordered in the hierarchy of importance. As normative standards that prescribe desirable modes of behavior, values are distinct from the properties of the object, such as its monetary value or utility value, and are irreducible to a particular form of behavior, such as instrumentally rational economic behavior (Racko 2011). Values are also distinct from behavior. While values guide behaviors across distinct contexts, behaviors are more context specific and more contingent on external reinforcement than are values (Meglino and Ravlin 1998). The occupational values of professionalism determine the norms, rules and ethical standards of a profession and enable its representatives to coordinate work based on shared goals and similar ways of identifying problems and solutions (Abbott 1988; Freidson 2001; Evetts 2013). ${ }^{1}$ These values enable representatives of a profession to secure autonomous control over the restricted domains of expert knowledge and practice (Abbott 1988) by determining the consistency with which they behave ethically toward their colleagues, clients and society (Freidson 2001; Ritzer and Walcak 1988). Occupational values of professionalism are socialized in the vocational education programs of universities as well as professional organizations and associations (Larson 1977; Evetts 2013).

Today the most highly regarded value classification is Schwartz's (1992) taxonomy of human values that at the more general level differentiates values into four categories: self-transcendence as opposed to self-enhancement, and openness to change as opposed to conservation (Hitlin and Piliavin 2004; Racko 2017c). This value classification integrates the value dimensions proposed by classical value taxonomies of Parsons (1951), Toennies (1957) and Weber (1978) (Racko 2011). It has been empirically validated in more than 60 countries worldwide (Schwartz 2006; Davidov et al. 2008). Schwartz's (1992) value taxonomy rarely has been used to measure professionals' values (Racko 2017b). However, research on the professionalism in general (Parsons 1954; Abbott 1988; Ritzer and Walcak 1988; Freidson 2001; Evetts 2013) and the accounting professionalism in particular (Loeb 1988; Huss and Patterson 1993; Duska and

\footnotetext{
1 We define professionalism in terms of the normative principles and formal rules that characterize a profession (Abbott 1988; Freidson 2001; Evetts 2013). Profession is defined as an occupational group that has autonomous control over expert "jurisdiction" or restricted domains of expert knowledge and practice. Professions legitimize their jurisdictional authority over a specific domain of specialized expert knowledge by securing autonomous control over the specification of the legitimate goals and means of profession (i.e., expertise, work techniques, ethics standards, etc.). The attainment of professional status by a specific occupational group is often interpreted as the outcome of "professional projects," or attempts to enact a "regulative bargain" in which scarce knowledge and skills are translated into legitimate recognition from states, in the form of professional status and monopoly over a jurisdictional domain (Larson 1977).
} 
Duska 2003; Mele 2005; Pakaluk and Cheffers 2011; Klein 2015) suggests that the occupational values of professionalism generically emphasize (1) public good, which according to Schwartz's (1992) taxonomy is a normative goal of selftranscendence values, and (2) independence and creativity, which for Schwartz (1992) is a normative goal of openness to change values. Below, we consider each of these values in turn.

\section{Self-Transcendence Values}

Accounting professionals pursue self-transcendence values, emphasizing the public good, to ensure that they are working to further the public interest rather than their own self-interest (Loeb 1988; Duska and Duska 2003; Mele 2005; Jackling et al. 2007; Lan et al. 2008; Pakaluk and Cheffers 2011). The codes of conduct of international and national professional associations, such as the International Federation of Accountants (IFAC), require accountants to act with integrity and honesty in relation to the interests of all stakeholders. These interests include not only those of investors, shareholders, creditors, business owners, customers and suppliers, but also the interests of society as a whole. IFAC explicitly states that acting in the interest of the public entails assessment of "the extent to which, for society, as a whole the benefits of the action, decision, or policy outweigh the costs" (IFAC 2012: 4). Therefore, accounting professionals are required to serve the interests of diverse stakeholders instead of the narrow interests of their employers and clients.

In pursuing the public interest, professionals should avoid conflicts of interest and should not deliberately misrepresent facts or deceive clients about the outcomes of their work. When accountants identify a threat to their occupational integrity resulting from a conflict of interest, they should resign from the client or from the employing organization. They should not exploit knowledge asymmetries in interaction with the recipients of knowledge, and they should not abuse their expertise or confidential information acquired as a result of professional and business relationships to gain an unfair advantage at clients' expense. Accountants are required to refrain from any actions that would discredit the reputation and interests of the profession.

Pursuit of public interest enables accounting professionals to maintain intra-occupational cohesion by facilitating collegial relations among occupational peers (Freidson 2001; Evetts 2013). It prevents accountants from engaging in opportunistic conduct, such as, for example, misrepresenting financial information or using this information for personal benefit in way that is detrimental to their peers. It also enables accountants to pursue their collective interest as members of a profession by maintaining cooperative relations with the members of other professions.

\section{Openness to Change Values}

Accounting professionals also pursue openness to change values, emphasizing independence and creativity, to maintain their autonomy in the creation, innovation and application of accounting expertise (Loeb 1988; Huss and Patterson 1993; Duska and Duska 2003; Pakaluk and Cheffers 2011; Bampton and Cowton 2013; Klein 2015). The international and national codes of accounting ethics require professionals to exercise independence in client assessment. In their professional work, accountants should provide an impartial assessment of their clients. Their occupational judgment should not be subordinated to external pressures, and they should avoid engagement in any relationships, partnerships or associations that may bias or unduly influence their independent judgement. Occupational independence also requires the maintenance and refinement of knowledge and skills that enable accountants to exercise objectivity and professional scepticism. Above all, accountants should not sell their occupational autonomy in exchange for any financial interest.

Although accountants use expertise that is to some extent codified and standardized, they also draw on abstract concepts and discretionary judgments to develop creative and ethical solutions under conditions of uncertainty. For example, accountants may face uncertainty when confronted with the ethical dilemma of pursuing either the public interest or their own self-interest in client evaluations. When faced with such an ethical dilemma, accountants are expected to demonstrate creativity in considering the ethical consequences of their actions and to act in accordance with the values of accounting professionalism.

Pursuit of autonomy enables professionals to maintain the legitimacy of their occupation by securing stakeholders' confidence in the impartial character of their work (Freidson 2001; Abbott 1988). The existing shareholders and potential investors of a company rely on accountants' audit reports to make informed decisions about their investments. When accountants relinquish their occupational autonomy by generating fraudulent audit reports in the narrow interests of their employers or clients, they not only undermine stakeholders' confidence in their work, but also shatter public trust in the institutional credibility of their profession (Cottel and Perlin 1990; Duska and Duska 2003).

In this paper, we examine how the economic rationalization of countries in which accounting professionals are employed influences their self-transcendence and openness to change values. We outline the theoretical rationale for our hypotheses below. 


\section{Impact of Economic Rationalization on Self-Transcendence Values}

Two theoretical perspectives have been developed on the normative effect of economic rationalization. The first perspective suggests that economic rationalization decreases self-transcendence values by transforming human action in accordance with the values of economic rationality, which is guided by the utilization of the most effective means for achievement of a self-interested end (Weber 1978; Tonnies 1996). According to this perspective, business professionals who are exposed to economically rationalized learning and work environments are likely to experience a decrease in self-transcendence values that emphasize public interest, by internalizing the values of economic rationality that emphasize self-interest (Ghoshal 2005; Ferraro et al. 2005; Huehn 2008). Extensive research links economics and business education programs that are guided economic rationality with a decrease in the public interest-oriented values and behaviors (Marwell and Ames 1981; Carter and Irons 1991; Frank et al. 1993; Yezer et al. 1996; Aspen Institute 2001; Frey and Meier 2005; Wang et al. 2011; Huehn 2014; Racko 2017a). Pursuit of self-interest is particularly strong in economics programs that are homogenously structured by the principles of neoclassical economics that emphasize instrumentally rational means-ends calculation (Frank et al. 1993; Racko et al. 2017).

Because economically rational action uses the most effective means to an end, the efficiency of such action is necessarily contingent on agents' ability to exercise power over means that are necessary to attain self-interest (Racko 2017a). Therefore, accountants who internalize the values of economic rationality, as a result of the economic rationalization process, are likely to seek power over means that are necessary to attain self-interested aims. For example, these accountants may use their membership in professional associations to disguise their self-interested behavior as disinterested conduct oriented toward the public good. They may use professional ethics standards instrumentally to gain a financial advantage from clients.

Accountants in economically rationalized countries are also more likely to use instrumentally rational strategies in interaction with their peers, because the pursuit of the public good would be an irrational obstacle to the maximization of self-interest (Tonnies 1996). In countries where work is homogenously structured by the values of economic rationality, the pursuit of instrumentally irrational ethical actions would entail a waste of time and effort, causing those who pursue them to be taken advantage of others who act in an instrumentally rational way (Miller 1999). The results of bargaining game experiments indicate that the more individuals perceive others to be economically rational, the more likely they are to behave in an economically rational way themselves (Kay et al. 2004; Molinsky et al. 2012). For example, accountants guided by economic rationality are likely to use their colleagues to develop a favorable assessment of a client firm from which they can gain a financial advantage. Although prior research has not examined the impact of economic rationalization on accountants' values, few studies have found a lower concern with ethical behavior in countries with a higher level of economic rationalization (Franke and Nadler 2008; Getz and Volkema 2001).

The alternative perspective is that economic rationalization increases the priority of self-transcendence values by increasing the material prosperity of individuals (Lerner 1958). In the economically rationalized countries with higher levels of material wealth and affluence, individuals are less constrained by the material necessities of survival and therefore are more likely to pursue self-transcendence values, emphasizing social well-being and protection of the environment (Maslow 1954; Inkeles and Smith 1974). According to this perspective, individuals in the wealthier, more economically rationalized countries can afford to pursue self-transcendence values because they are less pressured by the demands of material security. The wealth generated by economic rationalization increases material security, which in turn increases opportunities for the pursuit of nonmaterialistic goals. The key assumption of this perspective is that individuals who have satisfied their material goals are likely to pursue non-materialistic goals associated with self-actualization (Singhapakdi et al. 2001). Cross-national studies suggest that firms in economically rationalized countries are more likely to act ethically (Singhapakdi et al. 2011; Sanyal 2005), because they have more resources to implement ethics codes that regulate business practices (Thorelli 1981).

The law of diminishing marginal utility predicts that individuals experience a decline in the marginal satisfaction or benefit that they derive from an object of consumption such as material wealth (Gossen 1854). According to this law of economics, the increase in material wealth is likely to result in the decline of its marginal utility. Drawing on this reasoning, Inglehart (1977) predicted that economic rationalization is likely to result in the declining significance of material values due to the diminishing marginal utility of economic gains of the rationalization process. Inglehart proposed that, as individuals and societies become more prosperous, the striving for economic gains and survival (i.e., materialist values) paves the way to non-material concerns of selfexpression (i.e., post-materialist values). The predicted value shift was confirmed in a sample of 43 societies representing $70 \%$ of the world's population (Inglehart 1997) as well as in a sample of 81 societies representing $85 \%$ of the world's population (Inglehart and Welzel 2005). Therefore, we propose the following alternative hypotheses about the effects of economic rationalization on the self-transcendence values 


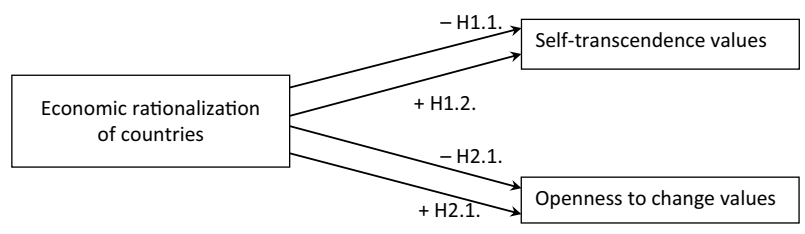

Fig. 1 Theoretical model of the hypothesized effects of economic rationalization on the occupational values of accounting professionals

of accounting professionals. The alternative hypotheses are visualized in Fig. 1.

Hypothesis 1.1. Accounting professionals are likely to attribute less importance to self-transcendence values in more economically rationalized countries.

Hypothesis 1.2. Accounting professionals are likely to attribute more importance to self-transcendence values in more economically rationalized countries.

\section{Impact of Economic Rationalization on Openness to Change Values}

Two opposing theoretical views have been proposed on the effect of economic rationalization on the openness to change values, which emphasize independence and creativity. On the one hand, economic rationalization decreases the priority of these values by standardizing human action in accordance with the logic of economically rational calculative thinking (Weber 1978). Accounting professionals who adopt economically rational calculative thinking as a result of the economic rationalization of their work are likely to become less concerned with openness to change, because they are likely to subordinate their independent and creative judgments to the logic of economic rationality. As long as individuals think in an economically rational way, the infinite diversity of human actions is reduced to a particular mode of action that entails means-ends calculation (Racko 2017a). Because calculative thinking conceives the end of an action merely as a means for further ends in the infinite chain of means-ends calculation, it restricts human choice to the selection of means (Dierksmeier 2011). Therefore, in the most generic form, when individuals think in the economically rational way, the thought of a rationally defined end establishes itself as a ruling power that subordinates action to its logic (Tonnies 1996). Because economically rational calculative thinking conceives non-rational action as a hindrance to self-interested maximization, accountants in economically rationalized countries may sacrifice their decision-making autonomy to maximize their economic utility.

Psychological research also suggests that internalization of the values of economic rationality as a result of economic rationalization is likely to undermine autonomous, intrinsic orientation to work as an end in itself by prioritizing extrinsic orientation to work as means to an end (Kasser et al. 2007). Moreover, individuals who act in an economically rational way are likely to sacrifice their independence and creativity by maximizing their usefulness to others (Riesman et al. 1970). According to this perspective, accountants in economically rationalized countries may prefer to maximize utility instead of pursuing occupational autonomy. For example, they may choose to trade their autonomy in client assessment in return for a financial advantage.

On the other hand, economic rationalization can also increase accountants' concern with openness to change, by providing resources necessary for their autonomy (Lerner 1958; Inkeles and Smith 1974; Inglehart 1997). By increasing material wealth, economic rationalization decreases material constraints on human choice. Poverty reduction liberates people from the pressures of economic survival, thus increasing their existential security and providing more opportunities for the exercise of choice. Using the World Value Survey data for 81 societies, Inglehart and Welzel (2005) found the economic rationalization of countries to be associated with an increased concerned with self-expression values emphasizing autonomy and creativity. Because accountants in the more economically rationalized countries are less likely to be constrained by the material necessities of survival, they are more likely to seek openness to change by pursuing autonomy in their interactions with stakeholders and thus more likely to provide impartial assessment of clients' accounts.

Further, economic rationalization can raise accountants' concern with openness to change by increasing the functional differentiation of work systems. According to Parsons' (1951) systems theory, economic rationalization results in the differentiation of work systems into functionally specialized subsystems. To facilitate inter-functional collaboration and adaptation to changes in the external environment, these functionally differentiated systems transmit and socialize values emphasizing openness to change. Accordingly, accountants in economically rationalized countries with a higher level of functional differentiation are more likely to pursue openness to change in order to reproduce and revise functionally specialized work systems. Therefore, we propose two alternative hypotheses about the effects of economic rationalization on the openness to change values of accounting professionals. These hypotheses are visualized in Fig. 1.

Hypothesis 2.1. Accounting professionals are likely to attribute less importance to openness to change values in more economically rationalized countries. 
Table 1 Sample size and social-level data for 28 countries (sorted by the national level of economic rationalization)

\begin{tabular}{|c|c|c|c|c|c|}
\hline Country & $N$ & $\begin{array}{l}\text { Economic ration- } \\
\text { alization }\end{array}$ & Individualism & $\begin{array}{l}\text { Uncertainty } \\
\text { avoidance }\end{array}$ & Power distance \\
\hline Norway & 38 & 4.98 & 69 & 50 & 31 \\
\hline Switzerland & 39 & 4.85 & 68 & 58 & 34 \\
\hline Denmark & 61 & 4.80 & 74 & 23 & 18 \\
\hline Ireland & 115 & 4.78 & 70 & 35 & 28 \\
\hline Netherlands & 74 & 4.72 & 80 & 53 & 38 \\
\hline Sweden & 85 & 4.72 & 71 & 29 & 31 \\
\hline Finland & 78 & 4.71 & 63 & 59 & 33 \\
\hline Austria & 22 & 4.70 & 55 & 70 & 11 \\
\hline Belgium & 82 & 4.68 & 75 & 94 & 65 \\
\hline Germany & 66 & 4.64 & 67 & 65 & 35 \\
\hline France & 57 & 4.64 & 71 & 86 & 68 \\
\hline UK & 73 & 4.64 & 89 & 35 & 35 \\
\hline Italy & 24 & 4.59 & 76 & 75 & 50 \\
\hline Spain & 62 & 4.54 & 51 & 86 & 57 \\
\hline Greece & 46 & 4.49 & 35 & 100 & 60 \\
\hline Israel & 35 & 4.44 & 54 & 81 & 13 \\
\hline Slovenia & 168 & 4.43 & 27 & 88 & 71 \\
\hline Portugal & 42 & 4.38 & 27 & 99 & 63 \\
\hline Czech Republic & 111 & 4.33 & 58 & 74 & 57 \\
\hline Slovakia & 87 & 4.26 & 52 & 51 & 100 \\
\hline Estonia & 150 & 4.25 & 60 & 60 & 40 \\
\hline Hungary & 67 & 4.19 & 80 & 82 & 46 \\
\hline Lithuania & 44 & 4.15 & 60 & 65 & 42 \\
\hline Poland & 79 & 4.14 & 60 & 93 & 68 \\
\hline Russia & 99 & 4.07 & 39 & 95 & 93 \\
\hline Turkey & 42 & 4.02 & 37 & 85 & 66 \\
\hline Bulgaria & 69 & 3.83 & 30 & 85 & 70 \\
\hline Ukraine & 119 & 3.59 & 25 & 95 & 92 \\
\hline
\end{tabular}

Hypothesis 2.2. Accounting professionals are likely to attribute more importance to openness to change values in more economically rationalized countries.

\section{Methods}

\section{Sample}

We used European Social Survey (ESS) data for 28 countries to test our hypotheses. ESS is a biannual and nationally representative survey of European countries. It is the only cross-national survey that measures the selftranscendence and openness to change values that are investigated in this study. Our sample included accounting professionals classified under unit-level category 2411 of the International Standard Classification of Occupations (1988 and 2008). We used a combined data of all seven available survey rounds administered from 2002 to 2014, because there were relatively small numbers of accounting professionals in each survey round. Additionally, there was a small number of accounting professionals $(<15)$ in three of the countries, i.e., Iceland, Croatia and Luxembourg. For this reason, we excluded these countries from the final data set.

When examining the effects of economic rationalization on accountants' values we controlled for the effects of Hofstede's (1980) cultural values found on the Geert Hofstede Web site (https://geert-hofstede.com/countries.html). The Hofstede Web site provides cultural value data for all countries included in ESS except for Cyprus. For this reason, we excluded the Cyprus data from our analyses.

To ensure that the assessment of the normative impact of the economic rationalization of countries was not confounded with the self-selection of accounting professionals into these countries because of cross-national migration, we excluded accounting professionals who had immigrated into the country in which they were surveyed (a total of $8 \%$ of all accounting professionals). 
In the final sample there were 2034 accounting professionals from 28 countries. Table 1 presents the distribution of accounting professionals by country. Of all accountants, $64.5 \%$ were female, $11 \%$ worked in public sector organizations, and $16.5 \%$ were members of a trade union. On average, accountants were 47.2 years old, had completed 15.24 years of full-time education, and worked $41.67 \mathrm{~h}$ per week.

\section{Measures}

\section{Values}

We measured self-transcendence and openness to change values using the measures of Schwartz et al.'s (2001) Portrait Values Questionnaire (PVQ) included in the European Social Survey (ESS) (Schwartz 2002: 284-286). The motivational goal of the self-transcendence values is to preserve social welfare and environment for the common good, and the motivational goal of openness to change values is to pursue independence and creativity (Schwartz 1992). PVQ asks participants to rate the importance of statements concerning their values on a six-point scale ranging from "very much like me" (1) to "not like me at all" (6). The measures of self-transcendence and openness to change values have demonstrated a reasonable meaning equivalence across countries (Davidov et al. 2008; Schwartz 2006). These measures exhibit adequate predictive validity, meaningfully differentiating between attitudes and behaviors that emphasize a concern for the common good and autonomy (Verkasalo et al. 2009; Schwartz 2006; Goodwin et al. 2004).

To adjust value measurement for variations in individual and national response styles, we standardized the calculation of value scores by centering them on the mean importance attributed to all value items, following Schwartz's (1992) recommendation. This was done by subtracting the value score attributed to each item from the average value score attributed to all PVQ items included in the ESS.

The measures of self-transcendence and openness to change values, composed of 5 and 4 items, respectively, had acceptable levels of reliability, i.e., Cronbach's alphas of .75 and .68 , respectively. Prior cross-national studies have found similar scale reliabilities for ESS PVQ value measures (Davidov et al. 2008; Verkasalo et al. 2009; Racko 2017c). A confirmatory factor analysis with the maximum likelihood estimation method using SPSS Amos 21 supported the two-factor model (SRMR $=0.058$; RMSEA $=0.076 ;$ GFI $=0.963 ; \chi^{2} / d f=12.16$ ) .

\section{Economic Rationalization}

Following an established practice in cross-national research (e.g., Hofstede 1980; Inglehart 1997), we measured the national level of economic rationalization in terms of national gross domestic product (GDP) per capita using the data provided by the World Bank (2012). The national level of economic rationalization represents the extent to which the economic systems of countries are guided by the values of economic rationality, which emphasize efficiency in the production, allocation and distribution of goods and services (Weber 1978). The GDP per capita measures the economic efficiency of countries in terms of the total market value of goods produced and services provided divided by its total population. In accordance with a conventional practice, we used a $\log$ transformation of a raw measure of GDP per capita to adjust for its uneven distribution due to skewness (Chen 2013). Table 1 differentiates 28 countries according to their levels of economic rationalization.

\section{Controls}

Cross-national studies suggest that the occupational values of accounting professionals are likely to be influenced by the three cultural values proposed by Hofstede (1980): individualism, uncertainty avoidance and power distance (Cohen et al. 1992; Roxas and Stoneback 1997; Smith and Hume 2005; Clements et al. 2009). Cultural values are commonly held normative standards in a population of a country that prescribe the desirable modes of behavior (Hofstede 1980).

First, Hofstede (1980) proposed that people in countries with an individualist culture tend to prioritize self-interest, assertiveness, competitiveness and a pragmatic approach to career mobility. They use instrumentally rational strategies of interaction with others and rarely consider the implications of their actions for society at large. They are little concerned about the ethical priorities of other individuals and tend to ignore social norms that obstruct the pursuit of their self-interest. A few studies suggest that accountants in individualist countries are less likely to engage in ethical behaviors, because they prefer self-interest to the common good (Cohen et al. 1992; Clements et al. 2009). In contrast, other studies have found that accountants in individualist countries are more likely to act ethically (Roxas and Stoneback 1997; Smith and Hume 2005).

Second, Hofstede (1980) predicted that in countries high uncertainty avoidance (UA) culture there is a lower tolerance of ambiguity and higher need for clarity and structure. In these countries, people tend to conform to established rules and norms. In organizations, employees perceive managers as experts who know all the correct answers. Roxas and Stoneback (1997) found accountants in high UA countries to be less likely to engage in ethical decision making. They suggested that, in these countries, accountants avoid ethical choices due to the uncertainty of making such a choice. Similarly, Clements et al. (2009) explained accountants' reluctance to behave ethically in high UA countries due to 
the fear that it might disrupt the established professional practices. Franke and Nadler (2008) also found individuals in countries with high UA to be less likely to exhibit ethical attitudes.

Third, in countries with a high power distance (PD) culture, people expect the power to be distributed unequally and accept such distribution (Hofstede 1980). In these countries, there is a high reliance on status symbols in the exercise of power and maintenance of established social hierarchies, as well as a high acceptance of inequalities in organizations, industries and society. In organizations, subordinates accept their inferior position and do not question the power and decisions of superiors. Clements et al. (2009) suggested that accountants in high PD countries are more likely to adopt an IFAC ethics code, because they tend to submit to hierarchical authority in the form of an authoritative international body. However, a number of cross-national studies have found that individuals in high PD countries are less concerned with ethical conduct, suggesting that, in these countries, individuals are more likely to comply with the requests of hierarchical authority even if such requests are unethical (Sanyal 2005; Scholtens and Dam 2007; Franke and Nadler 2008).

Because these three cultural values have been found to influence accountants' ethical attitudes and behaviors across countries, we included them in the data analyses as control variables. We used the cultural value scores provided by Geert Hofstede Web site (https://geert-hofstede.com/countries.html). Table 1 differentiates the 28 countries according to these cultural values.

We also controlled for the effects of individual-level characteristics that are recognized as theoretically important predictors of human values (Rokeach 1973; Meglino and Ravlin 1998; Hitlin and Piliavin 2004). Gender was coded as 1 (female) and 0 (male). Age was assessed as the actual age of participant. Years of education was measured as the number of years of full-time education completed. Religiosity was measured using an 11-point ordinal scale anchored by "not at all religious" and "very religious." Hours worked was measured as the total number of hours normally worked per week in the main job. Employment in a public sector organization was measured with a dummy variable coded as 1 (yes) and 0 (no). Membership of a trade union was measured using a dummy variable coded as 1 (member) and 0 (non-member). Organizational bureaucratization was measured using organizational size, which is a conventional practice in the research on bureaucracy (Blau 1970; Racko 2017c). This variable was measured using an ordinal scale that differentiates organizations in terms of the number of workers employed: (1) under 10, (2) 10-24, (3) 25-99, (4) $100-499$ and (5) 500 or more.

\section{Statistical Tests}

We tested our hypotheses using Pearson correlation and multilevel multiple regression (MMR) methods. This was done to differentiate the bivariate and multivariate effects of economic rationalization of accountants' values. The MMR method is typically used for the analysis of hierarchically clustered cross-national data, in which individual-level factors, such as personal values, are embedded in national-level factors, such as national level of economic rationalization. Because the MMR method assumes that the data are hierarchically nested and therefore interrelated, it avoids the shortcomings of the traditional ordinary least squares (OLS) regression method that is constrained by the assumption of the independence of observations. The OLS regression method is more likely to underestimate standard errors of predictors, which is particularly likely to occur for higherlevel predictors such as the national level of economic rationalization, and more likely to be subject to type I statistical errors in the analysis of large data sets (Raudenbush and Bryk 2002). However, to increase the validity of our findings, we triangulated the multivariate measurement of hypothesized effects using both MMR and OLSR methods. We conducted MMR analyses using the statistical software package SPSS 21 . The raw data were analyzed using the maximum likelihood estimation method. The significance level was set at 0.05 .

\section{Findings}

Table 2 presents the correlation matrix of the study variables. Table 3 presents the results of the multilevel multiple regression (MMR) analyses.

Hypotheses 1.1 and 1.2 predicted that accountants in the more economically rationalized countries are likely to attribute less and more importance, respectively, to selftranscendence values. The results of the Pearson correlation test indicated a significant and negative effect of economic rationalization on self-transcendence values $(r=-.140$, $p=.000)$. Similarly, the results of the multilevel multiple regression analysis indicated a significant and negative effect of economic rationalization on self-transcendence values, above and beyond the effects of individual- and social-level control variables (estimate $=-.272, \mathrm{SE}=.120, p<.05$ ). Thus, our findings provide support for Hypothesis 1.1.

Hypotheses 2.1 and 2.2 predicted that accountants in the more economically rationalized countries are likely to attribute less and more importance, respectively, to openness to change values. The results of Pearson correlation test indicated a significant and negative effect of economic rationalization on openness to change values $(r=-.110$, $p=.000)$. Consistent with the results of bivariate analysis, 


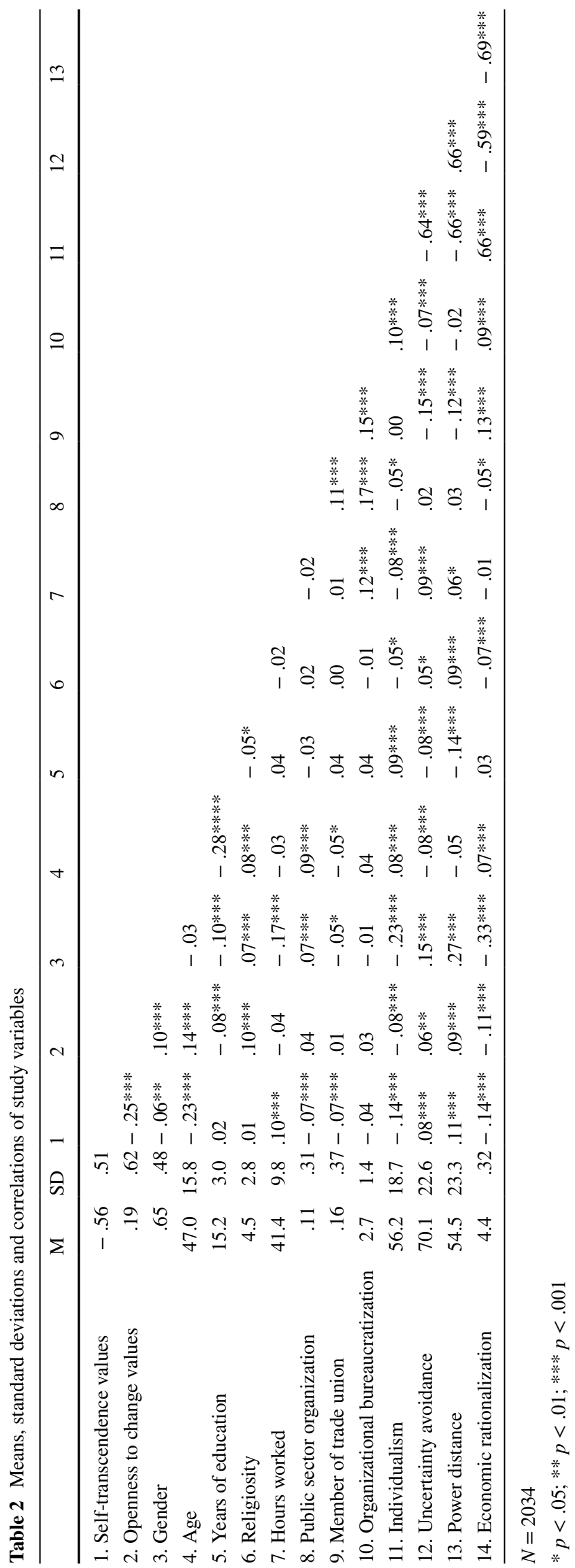

the results of multilevel multiple regression indicated a significant and negative effect of economic rationalization on openness to change values in the presence of control variables (estimate $=-.182, \mathrm{SE}=.088, p<.05$ ). Therefore, our findings support Hypothesis 2.1.

The conventional OLS regression method produced similar results. The results of OLS regressions are presented in Table 4. Economic rationalization had a negative and significant effect on self-transcendence values $(\beta=-.110$, $p=.002$ ), and a negative and significant effect on openness to change values $(\beta=-.097, p=.01)$.

Because economic rationalization was strongly correlated with the cultural values of individualism $(r=.65)$ and power distance $(r=-.69)$, we inspected the collinearity statistics in the OLS regression analyses. The two most widely used statistics for determining collinearity are tolerance and variance inflation factor (VIF) (Cohen et al. 2003). Tolerance measures the extent of variation in the predictor that is not explained by other predictors. VIF measures the extent to which the standard error of regression equation has been increased by multicollinearity. The tolerance statistic coefficients for all predictors in regression equations with selftranscendence and openness to change value measures as criteria were above 0.1 and VIF coefficients were below even the more conservative threshold $(\alpha>6)$ (Cohen et al. 2003). Therefore, collinearity statistics confirmed that collinearity among predictors did not affect the reliability of the regression analyses.

\section{Discussion and Conclusion}

There has been an increased concern with understanding environmental factors that undermine business professionals' values. Prior research has found that the occupational values of professionalism are weakened in vocational environments dominated by the values of economic rationality, such as business schools and management departments of universities (e.g., Ghoshal 2005; Huehn 2014; Racko et al. 2017). Our study examined how the occupational values of accounting professionals are influenced by the economic rationalization of countries, as an important macrostructural medium for the transmission of the values of economic rationality (Weber 1978; Ferraro et al. 2005). We focused on self-transcendence values, emphasizing public good, and openness to change values, emphasizing independence and creativity, as the values that generically represent the key values of accounting professionalism (Loeb 1988; Huss and Patterson 1993; Duska and Duska 2003; Mele 2005; Pakaluk and Cheffers 2011; Klein 2015). Below, we highlight the theoretical and practical implications of our findings. 
Table 3 Multilevel multiple regression analyses predicting the values of accounting professionals

\begin{tabular}{|c|c|c|c|c|c|c|c|c|}
\hline & \multicolumn{4}{|c|}{ Self-transcendence } & \multicolumn{4}{|c|}{ Openness to change } \\
\hline & Estimate & SE & $t$ & Sig. & Estimate & SE & $t$ & Sig. \\
\hline \multicolumn{9}{|l|}{ Individual-level variables } \\
\hline Gender & -.130 & .027 & -4.849 & .000 & .059 & .033 & 1.779 & .076 \\
\hline Age & -.008 & .001 & -9.892 & .000 & .005 & .001 & 5.180 & .000 \\
\hline Years of education & -.006 & .004 & -1.509 & .131 & -.008 & .005 & -1.599 & .110 \\
\hline Religiosity & .000 & .004 & .085 & .932 & .014 & .005 & 2.602 & .009 \\
\hline Hours worked & .003 & .001 & 2.589 & .010 & -.003 & .001 & -2.098 & .036 \\
\hline Public sector organization & -.072 & .037 & -1.944 & .052 & .027 & .047 & .580 & .562 \\
\hline Member of trade union & -.099 & .033 & -2.969 & .003 & .042 & .041 & 1.030 & .303 \\
\hline Organizational bureaucratization & .000 & .009 & -.050 & .960 & .012 & .011 & 1.094 & .274 \\
\hline \multicolumn{9}{|l|}{ Country-level variables } \\
\hline Individualism & -.002 & .002 & -1.091 & .287 & .000 & .002 & -.126 & .901 \\
\hline Uncertainty avoidance & -.002 & .002 & -1.508 & .146 & .001 & .001 & .565 & .578 \\
\hline Power distance & .000 & .002 & -.089 & .930 & .000 & .001 & -.026 & .979 \\
\hline Economic rationalization & -.272 & .120 & -2.267 & .033 & -.183 & .089 & -2.067 & .050 \\
\hline Log-likelihood & 2571.44 & & & & 3391.11 & & & \\
\hline Akaike information criterion & 2575.44 & & & & 3395.11 & & & \\
\hline Bozdogan's criterion & 2588.40 & & & & 3408.08 & & & \\
\hline
\end{tabular}

$N=2034$

Table 4 Ordinary least squares regression analyses predicting the values of accounting professionals

\begin{tabular}{|c|c|c|c|c|c|c|c|c|c|c|}
\hline & \multicolumn{5}{|c|}{ Self-transcendence } & \multicolumn{5}{|c|}{ Openness to change } \\
\hline & $\beta$ & SE & Sig. & Tolerance & VIF & $\beta$ & SE & Sig. & Tolerance & VIF \\
\hline \multicolumn{11}{|l|}{ Individual-level variables } \\
\hline Gender & -.124 & .026 & .000 & .833 & 1.201 & .045 & .033 & .079 & .833 & 1.200 \\
\hline Age & -.248 & .001 & .000 & .892 & 1.121 & .129 & .001 & .000 & .892 & 1.121 \\
\hline Years of education & -.039 & .004 & .107 & .880 & 1.137 & -.035 & .005 & .155 & .880 & 1.137 \\
\hline Religiosity & .016 & .004 & .484 & .980 & 1.020 & .064 & .005 & .006 & .981 & 1.020 \\
\hline Hours worked & .070 & .001 & .003 & .939 & 1.065 & -.052 & .001 & .029 & .939 & 1.065 \\
\hline Public sector organization & -.047 & .037 & .042 & .941 & 1.063 & .011 & .046 & .644 & .941 & 1.063 \\
\hline Member of trade union & -.075 & .032 & .001 & .905 & 1.105 & .024 & .040 & .317 & .905 & 1.105 \\
\hline Organizational bureaucratization & .003 & .009 & .909 & .911 & 1.097 & .029 & .011 & .234 & .911 & 1.097 \\
\hline \multicolumn{11}{|l|}{ Country-level variables } \\
\hline Individualism & -.098 & .001 & .005 & .422 & 2.370 & -.007 & .001 & .846 & .422 & 2.370 \\
\hline Uncertainty avoidance & -.119 & .001 & .000 & .472 & 2.120 & .022 & .001 & .522 & .472 & 2.120 \\
\hline Power distance & .048 & .001 & .180 & .397 & 2.520 & .001 & .001 & .987 & .397 & 2.519 \\
\hline Economic rationalization & -.110 & .056 & .002 & .417 & 2.401 & -.097 & .069 & .007 & .417 & 2.399 \\
\hline$F$ & 17.62 & & & & & 7.46 & & & & \\
\hline$R^{2}$ & .11 & & & & & .05 & & & & \\
\hline
\end{tabular}

$N=2034$

\section{Theoretical Implications}

Two competing perspectives exist on the normative effect of economic rationalization. While economic rationalization of countries can decrease the priority of self-transcendence and openness to change values by homogenizing professionals' actions in accordance with the values of economic rationality (Weber 1978; Tonnies 1996; Ritzer 2011), it can also increase the priority of these values by generating resources necessary to liberate them from the constraints of material necessities (Inkeles and Smith 1974; Inglehart and Welzel 2005). Consistent with the former perspective, our findings suggest that economic rationalization is likely to decrease accountants' self-transcendence and openness to 
change values. In general, we suggest that economic rationalization undermines professionals' commitment to these values by making their action more economically rational. However, we also suggest the theoretical mechanisms by which these two values decrease are likely to differ.

Economic rationalization is likely to undermine accountants' self-transcendence values by predisposing them to internalize the values of economic rationality that emphasize self-interest (Weber 1978; Tonnies 1996). Because, in its most generic form, economically rational action is guided by the utilization of the most effective means to an end, the efficiency of this action is necessarily contingent on individuals' ability to exercise control over the means necessary for the attainment of a self-interested end (Racko 2017a). Therefore, when economic rationality guides accountants' actions, any ethical considerations are approached as a means for maximizing self-interest, as opposed to the public good of stakeholders and peers (Fontrodona and Sison 2006; Huehn 2008).

Economic rationalization is also likely to decrease accountants' openness to change values by homogenizing their actions in accordance with the logic of economically rational calculative thinking. When calculative thinking guides action the autonomous choice between alternative modes of action becomes reduced to the selection of means necessary for the pursuit of a self-interested end (Weber 1978). Because calculative thinking views the end of an action simply as means for further ends in the infinite chain of means-ends calculations, it subordinates the attainment of many ends to the dominant end of self-interested maximization. As long as calculative thinking guides activity, the thought of a rationally pursued end determines the selection of means (Tonnies 1996). Therefore, the adoption of calculative thinking, as a result of economic rationalization, is likely to undermine accountants' independence and creativity by transforming their actions into passive responses to external necessities.

In general, our findings suggest that the national level of economic rationalization is an important social-level antecedent of accountants' values, which is likely to influence these values beyond the effects of cultural values. Prior studies have found accountants in countries with high individualism and uncertainty avoidance to be less engaged in ethical behaviors (Clements et al. 2009; Roxas and Stoneback 1997). Consistent with these results, we found that individualism and uncertainty avoidance exert a negative effect on accountants' self-transcendence values using the conventional OLS regression that assumes independence of observations. However, the results of multiple multilevel regressions, in which individual-level data were nested within country-level data, indicated that cultural values do not influence accountants' values. Therefore, methodologically, our findings highlight the importance of considering the hierarchically nested character of data in measuring the cross-national differences in values. Theoretically, the findings suggest that the national level of economic rationalization rather than the prevailing cultural values influences the changes in accountants' occupational values. Because we conceive of economic rationalization as a "normative" process guided by the values of economic rationality, we do not suggest that "economic" factors trigger changes in accountants' values at the expense of "normative" or "cultural" factors.

Moreover, our findings suggest that the effects of cultural values might confound the effects of economic rationalization on accountants' values. Consistent with Hofstede's (1980) seminal research, we identified a strong positive correlation between economic rationalization and cultural individualism $(r=.66)$. Moreover, economic rationalization and cultural individualism were consistently negatively correlated with accountants' values. It is thus plausible that economic rationalization may influence the changes in accountants' values by promoting individualist values that emphasize self-interest, self-assertiveness and competitiveness. This could be fruitfully examined in future research.

\section{Practical Implications}

Because accounting professionals in the more economically rationalized countries are less concerned with their occupational values, they can be more reluctant to fulfill their ethical obligations to clients and society. Occupational values of self-transcendence, emphasizing public good, and openness to change, emphasizing independence and creativity, enable accountants to elicit public trust in the quality of their work by acting with honesty, integrity and impartiality in relation to stakeholders (Loeb 1988; Duska and Duska 2003; Pakaluk and Cheffers 2011; Klein 2015). These values also enable accountants to maintain collegial relations with professional peers and to interact with them using shared ethical standards. In the more economically rationalized countries, where individual interactions are more instrumentally rational, accountants can be more reluctant to develop collegial relations with their peers out of fear that peers who act in an instrumentally rational way can take advantage of them. Further, because normative concern with economically rational conduct, which emphasizes instrumentally rational utilization of means for the achieving of self-interested ends, is higher in economically rationalized countries, accountants who are employed in these countries are more likely to compromise their occupational concern with the public good and autonomy for a financial advantage. This may prompt them to become involved in the types of unethical practices that have instigated corporate accounting scandals, thus undermining public confidence in the accounting profession. 
Prior research on the occupational values of accounting professionalism has demonstrated the ways in which these values can be socialized in accounting education programs (Huss and Patterson 1993; Mele 2005; Dellaportas 2006; Bampton and Cowton 2013). Our findings suggest that the socialization of these values is particularly important in countries with higher level of economic rationalization. In these countries, policy makers in universities, professional associations and service firms could ensure that education and training programs systematically integrate the values of accounting professionalism in curriculum development. Understanding and internalization of these values could help accountants act responsibly in relation to their stakeholders when facing ethical dilemmas.

To develop a more profound appreciation of the values of professionalism, policy makers in universities could supplement the teaching of the basic principles of accounting ethics with an interdisciplinary study of the role of professionals in organizations and society that integrates and compares the insights of the sociological, institutional and managerial perspectives on professions (Abbott 1988; Freidson 2001; Noordegraaf 2011; Muzio et al. 2013). This interdisciplinary learning approach is likely to raise accountants' awareness of the normative conflicts between the values of professionalism and the values of economic rationality that underpin the economic rationalization process. Awareness of the final axioms and behavioral outcomes of these distinct values can enable accounting professionals to select among different ends of action more responsibly and to understand the ethical implications of this selection for the accounting profession. It may also help them appreciate the intended and unintended consequences of economic rationalization of their professional values and behaviors. While economic rationalization increases productivity and material wellbeing, it does so at the expense of making professionals' behavior more instrumentally rational, which can predispose them to approach ethical standards merely as a means to an end.

We suggest that the socialization of professional values is likely to be a more effective mechanism to ensure ethical conduct of accountants rather than behavioral control using rules and regulations (Duska and Duska 2003; Bampton and Cowton 2013). This is because values are enduring normative standards that guide human behavior across distinct contexts while behaviors are more dependent on context and external control. Also, because bureaucratic regulation is generically based on the values of instrumentally rational administration that emphasize standardization and control of behavior (Weber 1978; Ritzer 2011; Racko 2017c), it might undermine professionals' concern with independence and public good by standardizing their actions in accordance with formal rules and by normatively enforcing instrumentally rational forms of behavior (Ritzer and Walcak 1988; Freidson 2001; Timmermans and Berg 2003; Racko 2017b). Professionals who internalize the values of instrumentally rational administration as a result of the bureaucratic regulation of their work may try to evade ethics rules or use them to their advantage.

\section{Limitations and Future Research Directions}

Our research is not without limitations. Value theory proposes that choices between a few generic values motivate human action (Schwartz 1992). Choices between a more differentiated set of work values that shape behaviors in occupational and organizational settings can mediate the normative effects of these generic values (Ros et al. 1999; Meglino and Ravlin 1998). We measured accountants' values using the measures of the generic value types introduced by Schwartz (1992). While Schwartz's (1992) value measures have been widely used in value socialization research and have been found to exhibit good predictive validity and reliability, they provide a generic operationalization of the values that are conventionally recognized as the key values of accounting professionalism (Duska and Duska 2003). Future research could triangulate the measurement of these generic values with the measurement of the value conflicts manifested in accounting work, for example, in terms of the pursuit of the public interest as opposed to self-interest in client assessment. Future research could also develop a more nuanced understanding of the cross-national variations in accountants' values by examining whether the negative effect of economic rationalization on self-transcendence values is stronger for accountants who are less concerned with openness to change. Research could also examine the moderating effect of cultural values on the relationship between the economic rationalization and accounting professionals' values.

We measured cross-national differences in values in a sample of 28 European countries using European Social Survey (ESS) data. We used these data because ESS is the only cross-national survey that includes the measures of Schwartz's (1992) value types. Future research could examine whether the normative effects of economic rationalization identified in this study occur in other regions of the world, such as Asia or North and South America.

An important methodological challenge in value socialization research is to differentiate the measurement of an environment's impact on individuals' values from their selfselection into that environment based on their pre-involvement values. To ensure that the measurement of the impact of the economic rationalization of countries on accountants' values was not confounded by their immigration into these countries based on their prior values we focused only on 
accountants who were born in the country in which they were surveyed, comprising $92 \%$ of all accountants. Future research could use a longitudinal research design to examine the impact of the national level of economic rationalization on changes in accountants' values over time.

Another interesting direction for future research would be to examine whether the economic rationalization of industries and professional service firms in which accountants are employed moderate the normative effects of the national economic rationalization. Research could also examine whether accountants' employment in organizations that subscribe to ethics codes of professional associations and their enrolment in academic programs that are certified by such associations decrease the normative effect of economic rationalization. Moreover, research could fruitfully investigate the moderating role of economically rationalized accounting education in the normative effect of the economic rationalization. We suggest that enrollment in accounting programs where the curriculum is homogenized in accordance with the values of economic rationality is likely to increase the negative effect of the national economic rationalization on accountants' values. Future research could also compare the effects of the economic rationalization of work and learning on the values of business professionals specializing in accounting, finance, business consulting and management, as well as the values of the representatives of other professions.

\section{Compliance with Ethical Standards}

Conflict of interest Girts Racko declares that he has no conflict of interest.

Ethical Approval All procedures performed in studies involving human participants were in accordance with the ethical standards of the institutional and/or national research committee and with the 1964 Declaration of Helsinki and its later amendments or comparable ethical standards.

Informed Consent Informed consent was obtained from all individual participants included in the study.

Open Access This article is distributed under the terms of the Creative Commons Attribution 4.0 International License (http://creativecommons.org/licenses/by/4.0/), which permits unrestricted use, distribution, and reproduction in any medium, provided you give appropriate credit to the original author(s) and the source, provide a link to the Creative Commons license, and indicate if changes were made.

\section{References}

Abbott, A. (1988). System of professions. Chicago: Chicago University Press.

Bampton, R., \& Cowton, C. J. (2013). Taking stock of accounting ethics scholarship: A review of the journal literature. Journal of Business Ethics, 114, 549-563.
Blau, P. M. (1970). A formal theory of differentiation in organizations. American Sociological Review, 35, 201-218.

Carter, J. R., \& Irons, M. D. (1991). Are economists different and if so, why? Journal of Economic Perspectives, 5(2), 171-177.

Chen, M. K. (2013). The effect of language on economic behaviour: Evidence from savings rates, health behaviors, and retirement assets. American Economic Review, 103(2), 690-731.

Clements, C. E., Neill, J. D., \& Stovall, O. S. (2009). The impact of cultural differences on the convergence of international accounting codes of ethics. Journal of Business Ethics, 90, 383-391.

Cohen, J., Cohen, P., West, S. G., \& Aiken, L. S. (2003). Applied multiple regression/correlation analysis for the behavioral sciences (3rd ed.). Mahwah, NJ: LEA.

Cohen, J., Pant, L., \& Sharp, D. (1992). Cultural and socioeconomic constraints on international codes of ethics: Lessons from accounting. Journal of Business Ethics, 11(9), 687-700.

Cottel, P. G., \& Perlin, T. M. (1990). Accounting ethics: A practical guide for professionals. Westport: Quorum Books.

Davidov, E., Schmidt, P., \& Schwartz, S. H. (2008). Bringing values back in: The adequacy of the European Social Survey to measure values in 20 countries. Public Opinion Quarterly, 72, 420-445.

Dellaportas, S. (2006). Making a difference with a discrete course on accounting ethics. Journal of Business Ethics, 65, 391-404.

Dierksmeier, C. (2011). The freedom-responsibility nexus in management philosophy and business ethics. Journal of Business Ethics, 101(4), 263-283.

Duska, R. F., \& Duska, B. S. (2003). Accounting Ethics. Oxford: Blackwell.

Evetts, J. (2013). Professionalism: Value and ideology. Current Sociology, 61(5-6), 778-796.

Ferraro, F., Pfeffer, J., \& Sutton, R. I. (2005). Economics language and assumptions: How theories can become self-fulfilling. Academy of Management Review, 30, 8-24.

Fontrodona, J., \& Sison, A. J. G. (2006). The nature of the firm, agency theory and shareholder theory: A critique from philosophical anthropology. Journal of Business Ethics, 66, 33-42.

Frank, R. H., Gilovich, T., \& Regan, D. T. (1993). Does studying economics inhibit cooperation? Journal of Economic Perspectives, 7, 159-171.

Franke, G. R., \& Nadler, S. S. (2008). Culture, economic development, and national ethical attitudes. Journal of Business Research, 61, 254-264.

Freidson, E. (2001). Professionalism: The third logic. London: Polity.

Frey, B., \& Meier, S. (2005). Selfish and indoctrinated economists? European Journal of Law and Economics, 19, 165-171.

Getz, K. A., \& Volkema, R. J. (2001). Culture, perceived corruption, and economics: A model of predictors and outcomes. Business and Society, 40(1), 7-30.

Ghoshal, S. (2005). Bad management theories are destroying good management practices. Academy of Management Learning and Education, 4, 75-91.

Goodwin, R., Costa, P., \& Adonu, J. (2004). Social support and its consequences: 'Positive' and 'deficiency' values and their implications for support and self-esteem. British Journal of Social Psychology, 43(3), 465-474.

Gossen, H. H. (1854). Entwickelung der Gesetze des menschlichen Verkehrs, und der daraus fließenden Regeln für menschliches Handeln [Development of the laws of human intercourse, and the rules following therefrom for human action]. Braunschweig: Friedrich Vieweg und Sohn.

Graafland, J. J., \& Van de Ven, B. W. (2011). The credit crisis and the moral responsibility of professionals in finance. Journal of Business Ethics, 103(4), 605-619.

Hitlin, S., \& Piliavin, J. A. (2004). Values: Reviving and dormant concept. Annual Review of Sociology, 30, 359-393. 
Hofstede, G. (1980). Culture's consequences: International differences in work-related values. London: Sage.

Hofstede, G. (2001). Culture's consequences: Comparing values, behaviours, institutions, and organizations across nations. Thousand Oaks, CA: Sage Publications.

Huehn, M. P. (2008). Unenlightened economism: The antecedents of bad corporate governance and ethical decline. Journal of Business Ethics, 81(4), 823-835.

Huehn, M. P. (2014). You reap what you sow: How MBA programs undermine ethics. Journal of Business Ethics, 81(4), 823-835.

Huss, H. F., \& Patterson, D. M. (1993). Ethics in accounting: Values education without indoctrination. Journal of Business Ethics, 12, 235-243.

Inglehart, R. (1977). The silent revolution: Changing values and political styles among Western publics. Princeton: Princeton University Press.

Inglehart, R., \& Welzel, C. (2005). Modernisation, cultural change and democracy: The human development sequence. Cambridge: Cambridge University Press.

Inkeles, A., \& Smith, D. (1974). Becoming modern: Individual changes in six developing societies. Cambridge, MA: Harvard University Press.

Institute, Aspen. (2001). Where will they lead? MBA student attitudes about business and society. New York: Aspen Institute for Social Innovation Through Business.

International Federation of Accountants. (2012). A definition of public interest. Retrieved on October 16, 2017. https://www.ifac.org/system/files/publications/files/PPP $\% 205 \% 20 \% 282 \% 29$.pdf.

Jackling, B., Cooper, B. J., Leung, P., \& Dellaportas, S. (2007). Professional accounting bodies' perceptions of ethical issues, causes of ethical failure and ethics education. Managerial Auditing Journal, 22(9), 928-944.

Kasser, T., Cohn, S., Kanner, A. D., \& Ryan, R. M. (2007). Some costs of American corporate capitalism: A psychological exploration of value and goal conflicts. Psychological Inquiry, 18, 1-22.

Kay, A. C., Wheeler, S. C., Bargh, J. A., \& Ross, L. (2004). Material priming: The influence of mundane physical objects on situational construal and competitive behavioral choice. Organisational Behaviour and Human Decision Processes, 95, 83-96.

Klein, G. (2015). Ethics in accounting: A decision-making approach. New York: Wiley.

Lan, G., Ma, Z., Cao, J. A., \& Zhang, H. (2008). Comparison of personal values of Chinese accounting practitioners and students. Journal of Business Ethics, 88, 59-76.

Larson, M. S. (1977). The rise of professionalism. Berkeley: University of California Press.

Lerner, D. (1958). The passing of traditional society: Modernizing the Middle East. New York: Free Press.

Loeb, S. E. (1988). Teaching students accounting ethics: Some crucial issues. Issues in Accounting Education, 3, 316-329.

Lynnette, S. M., \& Davis, J. R. (2004). Perceptions of dishonesty among two-year college students: Academic versus business situations. Journal of Business Ethics, 51(1), 63-73.

Marwell, G., \& Ames, R. (1981). Economists free side, does anyone else?: Experiments on the provision of public goods, IV. Journal of Public Economics, 15(3), 295-310.

Maslow, A. H. (1954). Motivation and personality. New York: Harper and Row.

Meglino, B. M., \& Ravlin, E. C. (1998). Individual values in organizations: Concepts, controversies and research. Journal of Management, 24, 351-389.

Mele, D. (2005). Ethical education in accounting. Integrating rules, values and virtues. Journal of Business Ethics, 57, 97-109.
Mele, D., Rosanas, J. M., \& Fontrodona, J. (2017). Ethics in finance and accounting: Editorial introduction. Journal of Business Ethics, 140, 609-613.

Miller, D. T. (1999). The norm of self-interest. American Psychologist, $54,1053-1060$

Molinsky, A., Grant, A. M., \& Margolis, J. D. (2012). The bedside manner of homo economicus: How and why priming an economic schema reduces compassion. Organizational Behavior and Human Decision Processes, 119, 27-37.

Muzio, D., Brock, D. M., \& Suddaby, R. (2013). Professions and institutional change: Towards an institutionalist sociology of the professions. Journal of Management Studies, 50, 699-721.

Noordegraaf, M. (2011). Risky business: how professionals and professionals fields (must) deal with organizational issues. Organization Studies, 32, 1349-1371.

Pakaluk, M., \& Cheffers, M. (2011). Accounting ethics. Sutton: Allen David Press.

Parsons, T. (1951). Social system. London: Routledge and Kegan Paul.

Parsons, T. (1954). Professional and social structure. In T. Parsons (Ed.), Essays in sociological theory. Glencoe: Free Press.

Racko, G. (2011). On the normative consequences of economic rationality: A case study of a Swedish economics school in Latvia. European Sociological Review, 27, 772-789.

Racko, G. (2017a). The values of economics. Journal of Business Ethics. https://doi.org/10.1007/s10551-017-3442-5.

Racko, G. (2017b). Bureaucratization and medical professionals' values: A cross-national analysis. Social Science and Medicine, 180, $76-84$

Racko, G. (2017c). Values of bureaucratic work. Sociology-The Journal of the British Sociological Association, 51(2), 374-392.

Racko, G., Strauss, K., \& Burchell, B. (2017). Economics education and value change: The role of program normative homogeneity and peer influence. Academy of Management Learning and Education. https://doi.org/10.5465/amle.2014.0280.

Raudenbush, A. S., \& Bryk, S. W. (2002). Hierarchical linear models. Thousand Oaks: Sage Publications.

Riesman, D., Glazer, N., \& Denny, R. (1970). Lonely crowd. New Haven: Yale University Press.

Ritzer, G. (2011). The McDonaldization of society. Thousand Oaks: Pine Forge Press.

Ritzer, G., \& Walcak, D. (1988). Rationalization and Deprofessionalization of Physicians. Social Forces, 67, 1-22.

Rokeach, M. (1973). Nature of human values. New York: Free Press.

Ros, M., Schwartz, S. H., \& Surkiss, S. (1999). Basic individual values, work values, and the meaning of work. Applied Psychology, 48(1), 49-71.

Roxas, M. L., \& Stoneback, J. Y. (1997). An Investigation of the ethical decision-making process across varying cultures. International Journal of Accounting, 32(4), 503-535.

Sanyal, R. (2005). Determinants of bribery in international business: The cultural and economic factors. Journal of Business Ethics, 59, 139-145.

Satava, D., Caldwell, C., \& Richards, L. (2006). Ethics and the auditing culture: Rethinking the foundation of accounting and auditing. Journal of Business Ethics, 64, 271-284.

Scholtens, B., \& Dam, L. (2007). Cultural values and international differences in business ethics. Journal of Business Ethics, 75, 273-284

Schwartz, S. H. (1992). Universals in the content and structure of values: Theoretical advances and empirical tests in 20 countries. In M. Zanna (Ed.), Advances in experimental social psychology. New York: Academic Press.

Schwartz, S. (2002). A proposal for measuring value orientations across nations. European Social Survey (items PVQ listed pages 284-286). Accessible online: http://www.europeansocialsurvey. 
org/docs/methodology/core_ess_questionnaire/ESS_core_questionnaire_human_values.pdf.

Schwartz, S. H. (2006). Value orientations: Measurement, antecedents and consequences across nations. In R. Jowell, C. Roberts, R. Fitzgerald, \& G. Eva (Eds.), Measuring attitudes cross-nationally-Lessons from the European Social Survey (pp. 169-203). London: Sage.

Schwartz, S. H., Melech, G., Lehrnami, A., Burgess, S., Harris, M., \& Owens, V. (2001). Extending the crosscultural validity of the theory of basic human values with a different method of measurement. Journal of Cross-Cultural Psychology, 32, 519-542.

Sen, A. (1987). On ethics and economics. New York: Basil Blackwell Publishers.

Singhapakdi, A., Marta, J. K. M., Rao, C. P., \& Cicic, M. (2001). Is cross-cultural similarity an indicator of similar marketing ethics? Journal of Business Ethics, 32, 55-68.

Smith, A., \& Hume, E. C. (2005). Linking culture and ethics: A comparison of accountants' ethical belief systems in the individualism/collectivism and power distance contexts. Journal of Business Ethics, 62, 209-220.

Thorelli, H. B. (1981). Consumer policy for the third world. Journal of Consumer Policy, 5(3), 197-211.

Timmermans, S., \& Berg, M. (2003). The gold standard: The challenge of evidence-based medicine and standardization in health care. Philadelphia: Temple University Press.
Tonnies, F. (1957). Community and society. East Lansing: Michigan State University Press.

Tonnies, F. (1996). Community and society. New Brunswick: Transaction Publishers. Originally published Michigan State University Press.

Verkasalo, M., Lonnqvist, J. E., Lipsanen, J., \& Helkama, K. (2009). European norms and equations for a two dimensional presentation of values as measured with Schwartz's 21-item portrait values questionnaire. European Journal of Social Psychology, 39, 780-792.

Wang, L., Malhotra, D., \& Murnighan, J. K. (2011). Economics education and greed. Academy of Management Learning and Education, 10, 643-660.

Weber, M. (1978). Economy and society. Stanford: Stanford University Press.

World Bank. (2012). Retrieved from the web link: http://data.worldbank.org/indicator.

Yezer, A. M., Goldfarb, R. S., \& Poppen, P. J. (1996). Does studying economics discourage cooperation? Watch what we do, not what we say or how we play. Journal of Economic Perspectives, 10(1), 177-186. 